\title{
TERRITÓRIO: CONFLITOS E REPRODUÇÃO DO CAPITAL EM MOÇAMBIQUE
}

\author{
Ernesto Jorge Macaringue \\ Escola Superior de Hotelaria e Turismo - Universidade Eduardo Mondlane, Inhambabe, Moçambique \\ jorgitomapilele@gmail.com \\ Thiago Sebastiano de Melo \\ Centro de Excelência em Turismo - Universidade de Brasília, Brasília-DF, Brasil \\ sebastianodemelo@gmail.com
}

\begin{abstract}
RESUMO
Em qual medida os processos de administração da terra, que se baseiam na concepção do território único, estão no centro dos conflitos pelo seu acesso, controle e gestão em Moçambique? As disputas pelo acesso, controle e gestão da terra como meio universal de criação de riqueza e bem-estar social, envolvem os sujeitos do campo que são os membros das comunidades locais, os agentes dos órgãos do governo que administram a terra e os que querem acumular ou ampliar seu dinheiro com ela. Nesse contexto, o nosso objetivo é problematizar a concepção do território único, que entendemos ofuscar e aniquilar a importância material da comunidade local, que pode ser resumida como uma categoria espacial vital na organização e reprodução social camponesa; subsidiando as vozes que sempre reivindicaram a necessidade de uma reforma agrária. Os dados usados no debate provêm de várias fontes: acervos dos órgãos do Estado, relatórios de pesquisas e fontes orais de diferentes personalidades. Ao sistematizar tais informações apontamos que a perda da sociobiodiversidade está atrelada ao moinho que tritura interações metabólicas nas quais a dignidade da vida é pilar (territórios campesinos) para subsumir a vida ao imperativo do capital.
\end{abstract}

Palavras-chave: Território Único. Comunidade Local. Conflitos Territoriais. Sociobiodiversidade.

\section{TERRITORY: CONFLICTS AND REPRODUCTION OF CAPITAL IN MOZAMBIQUE}

\begin{abstract}
To what measure the processes of land administration, which are based on the notion of sole territory, are at the core of the confilcts for its access, control and management in Mozambique? The disputes for access, control and management of the land, as universal means of creating wealth and social welfare, involve - obviously - the Subjects of the field (members of local communities), governmental power agents who manage the land, and those who dream about amassing or broadening their wealth with it. In this context, our objective is to problematize the concept of sole territory, which we understand to outshine and anihilate the material importance of the Local Community, as it sustains the legal interpretation of this category, which could be summarized as a spatial category, vital in the peasant social organization and reproduction; subsidizing the voices who have always reclaimed the need for an Agrarian Reform. The data used on the debate come from many sources; State-owned organs' databases, research reports and oral sources from different personalities. By systematizing such information, we postulate that the loss of biodiversity is intertwined to the mill which grinds metabolic interactions, interactions on which the dignity of life is a main pillar (peasasnt territories), to subjugate life to the imperative of capital.
\end{abstract}

Keywords: Sole Territory. Local Community. Territorial Conflicts. Sociobiodiversity.

\section{INTRODUÇÃO}

Os debates que se centram no uso do território em Moçambique, nos últimos anos, prestam mais atenção às dinâmicas territoriais nas comunidades locais onde há: exploração dos minérios, implementação de programas vinculados à produção de commodities e participação de iniciativas privadas e em situações nas quais os interesses de acumulação são ocultados por ações de assistência técnica e humanitária. 
Para exemplificar há os programas que têm sido objeto de muitas críticas porque ainda na fase inicial estão a provocar profundas transformações territoriais. Podemos citar o ProSavana-JBM ou os projetos de reabilitação e restruturação das infraestruturas de escoamento como estradas, linhas férreas e portos, e, mais especificamente, os corredores que estão sendo implementados em áreas ricas em biodiversidade. Há também os projetos de exploração de minérios nas províncias de Tete, Cabo Delgado, e Nampula. E os projetos turísticos que estão sendo inseridos nas áreas de proteção ambiental e que vestem a capa de conservação da biodiversidade.

Paradoxalmente esses programas e iniciativas privadas são consideradas como parte dos processos de desenvolvimento socioeconômico nacional. As dinâmicas territoriais que ocorrem em comunidades locais, estão vinculadas às políticas que promovem a livre concorrência, submetendo os camponeses àquilo que Harvey (2005) chama de reserva de mão-de-obra sem-terra. Obviamente, o processo de inserção de imaginários de acumulação do capital em territórios das comunidades camponesas em Moçambique ocorre com suporte legal que inclui a Política Nacional de Terras (PNT), Lei de Terras, Regulamento de Lei de Terras, e outros dispositivos legais.

O atual pacote de legislação da terra é considerado pelos autores, por exemplo, Negrão (2008) que se identificam com a coletivização da terra como um dos melhores, dado que, ao permitir a coexistência de direitos formais e consuetudinários, procura responder à demanda da terra sem comprometer os direitos adquiridos pelos camponeses. No entanto, em função dos conflitos que são relatados, podemos dizer que o modelo da governança da terra seguido em Moçambique é objeto de questionamentos quanto à efetiva participação dos membros ou grupos de famílias que compõem comunidades locais. Assim, o que está por detrás dos conflitos de terra em comunidades locais? Em função da ginástica dos governantes, podese dizer que a vontade do governo em obter avultadas receitas tributárias joga um papel importante para os atos administrativos que desprezam a importância de participação dos membros ou grupos de famílias que compõem as comunidades locais que tem suas existências atreladas aos seus territórios de vida.

Para citar as indústrias extrativas, há os conflitos que são reportados, por exemplo, em Moatize, na província de Tete, em Temane, no distrito de Inhassoro em Inhambane; no distrito de Moma em Nampula; nos distritos de Palma e Mocimboa da Praia em Cabo Delgado. Estas citações ilustram somente os casos mais reportados na atualidade que evidenciam parcialmente a vontade do Governo para introduzir projetos econômicos que aparentemente irão providenciar volumes robustos de receitas tributárias nos cofres do Estado, e, supostamente, postos de emprego. Por outro lado, analisando as formas como são introduzidos os projetos econômicos, fica-se com a ideia de que há segmentos do Governo que adotam postura de arrogância e desprezo perante os interesses e direitos das comunidades locais.

$\mathrm{Na}$ tentativa de aprofundar a interpretação do modelo de governança da terra, que tem sua base de sustentação na concepção adotada em Moçambique de território único, procuramos problematizar os limites da soberania. Estes nos parecem estar no bojo dos conflitos pelas disputas de controle, acesso e uso da terra. Consideramos ser pertinente a compreensão da importância material da comunidade local, partindo do pressuposto de que o seu conteúdo nos remete a considerar que se trata de uma categoria vital na organização e reprodução social dos camponeses.

Outrossim, a agenda do poder executivo sinaliza ventos de mudança para a atual Política Nacional de Terras, como será abordado adiante. Esta mudança precisa eleger a participação da comunidade local no debate da governança da terra com o olho fixo na categoria do território vivido, subsidiando as vozes que sempre reivindicaram uma reforma agrária completa. Esta reforma agrária deverá sustentar-se nas práticas e modos de vida dos sujeitos, que tem os bens comuns - solo, subsolo, água subterrânea e superficial, fauna, flora, ar, minérios, etc. - como elementos vitais para a existência.

Para o debate dos territórios vividos foi realizada revisão bibliográfica, consulta documental e de interação com os diferentes segmentos sociais como profissionais do setor de cadastro de terra, os membros das comunidades locais, visitadas em diferentes contextos desde o ano de 2000 até os dias que correm, líderes de confissões religiosas, educadores do campo filiados às organizações da sociedade civil, entre outros. Os dados analisados neste artigo compreendem dados estatísticos, discursos, posições de dirigentes e dos promotores de desenvolvimento, fatos observados no campo e informações obtidas em diálogos com a população. 


\section{A REFORMA AGRÁRIA: O QUE SE PRETENDE ALTERAR NA ATUAL POLÍTICA NACIONAL DE TERRAS?}

O Presidente da República e Chefe do Governo de Moçambique, Vossa Excelência Filipe Jacinto Nyusi, procedeu no dia 16 de julho de 2020, no Município da Matola em Maputo, o lançamento do Processo de Auscultação Pública sobre a Revisão da Política Nacional de Terras (LANÇAMENTO, 2020). Esse evento político ocorreu num contexto em que o debate das questões que envolvem o acesso à terra e outros bens naturais, para vários fins, vem suscitando posicionamentos diferentes e contraditórios. Pode-se dizer que o regime jurídico de posse da terra é o que aparece claramente com posições antagônicas: privatização da terra ou estatização da terra?

Além desses aspectos, o processo de implementação da atual política, que nunca se efetivou na plenitude, tem se deparado com arbitrariedades na realização das consultas comunitárias. Essas ocorrem no cálculo das compensações ou de indenizações e na canalização às comunidades locais dos $20 \%$ provenientes das receitas dos investimentos econômicos em seus territórios.

Perante estes fatos e com a posição política do governo no ato do lançamento do Processo de Auscultação Pública sobre a Revisão da Política Nacional de Terras afirmando a manutenção do regime de posse terra - propriedade do Estado -, há que se perguntar: que inovações serão trazidas na nova Política Nacional de Terras?

Não se pretende neste texto antever as respostas daquilo que resultará no âmbito do trabalho do Fórum de Consulta de Terras. Nossa intenção é promover um debate crítico sobre o território comunitário, comumente chamado Comunidade Local. Entende-se que Comunidade Local é categoria de análise vital para compreensão da organização e reprodução social dos camponeses em Moçambique. Ao se colocar na agenda do debate o conceito de Comunidade Local, a verdadeira categoria do território vivido no campo Moçambicano, nossa outra intenção é o debate inserido no Processo de Auscultação Pública sobre a Revisão da Política Nacional de Terras, como subsidio às vozes que reivindicam a manutenção da posse estatal ou coletiva de terra.

De acordo com o comunicado da presidência (PRESIDÊNCIA, 2020, s/p.),

[...] a reforma da Política Nacional de Terras visa responder aos desafios da consolidação das estruturas da economia do mercado, nomeadamente, o aumento do número de habitantes perante um recurso não renovável, as mudanças climáticas, a necessidade de compensação da biodiversidade, a emergência dos megaprojectos e o acelerado crescimento da população urbana. "Pretendemos que a fase que hoje lançamos termine com a adoção de um quadro de políticas e regulamentos sobre a terra que seja mais, e que promova avanços da nossa sociedade e na economia. Não queremos retroceder nesta nossa caminhada que iniciámos em 1975 ao libertar a terra e os homens".

No que diz respeito aos procedimentos que serão seguidos referiu que,

[...] o governo, ao assumir o compromisso de avançar com a reforma do quadro legal e institucional de terra, ficou com a tarefa de guiar o processo, incluindo garantir uma auscultação pública mais alargada e abrangente. "A partir de hoje iremos ao terreno, com o objectivo de ouvir os cidadãos, famílias, comunidades locais, empresas, organizações cívicas e religiosas, academia entre outros, assim como aglomerados populacionais como povoações, distritos, províncias, cidades e vilas, e em todos os quadrantes sobre como devemos aproveitar este recurso mais precioso, a terra", disse.

A auscultação pública é a terceira etapa da revisão do quadro legal de terra, após o lançamento do processo na IX Sessão do Fórum de Consultas sobre Terras, em novembro de 2017, pelo Presidente da República, seguido de criação, em abril de 2018, de uma Comissão Técnica específica.

Está claro que o debate da reforma agrária vem ocorrendo há tempos. As pesquisas do Núcleo de Estudos de Terras da Universidade Eduardo Mondlane (NET-UEM), do Instituto do Cruzeiro do Sul e artigos avulsos de autores nacionais e estrangeiros testemunham o debate sobre a reforma agrária em Moçambique.

O atual pacote da legislação de terra inclui as diretivas básicas, nomeadamente: a Constituição da República, a Política Nacional de Terras e as respectivas Estratégias de Implementação, Resolução 10/95; a Lei de Terra $n^{\circ} 19 / 97$ de $1^{\circ}$ de Outubro e o respectivo Regulamento da Lei de Terras, Decreto $n^{\circ}$. $66 / 98$ de 8 de Dezembro. 
Uma das inovações é a introdução das consultas comunitárias e o reconhecimento dos direitos costumeiros. No caso específico das consultas comunitárias a sua justificativa é pelo fato de ter se constatado o conteúdo físico da categoria de Comunidade Local:

\begin{abstract}
Comunidade Local: agrupamento de famílias e indivíduos, vivendo numa circunscrição territorial de nível de localidade ou inferior, que visa a salvaguarda de interesses comuns através da protecção de áreas habitacionais, áreas agrícolas, sejam cultivadas ou em pousio, florestas, sítios de importância cultural, pastagens, fontes de água e áreas de expansão ( $n^{\circ} 1$ do artigo 1 da Lei de Terras $n^{\circ} 19 / 97$ de $1^{\circ}$ de Outubro).
\end{abstract}

Como se pode ver, o conteúdo de uma comunidade local inclui, primeiro, um espaço físico, segundo, um agrupamento de famílias e indivíduos, terceiro, interesses comuns dos sujeitos que compõem os agrupamentos citados, que vão além dos limites das parcelas onde se circunscrevem os direitos individuais. Interessante observar que há um reconhecimento de que os camponeses se preocupam com a proteção de áreas habitacionais e áreas agrícolas, sejam cultivadas ou em pousio, das florestas, dos sítios de importância cultural, das pastagens, fontes de água e áreas de expansão.

A reforma agrária é um assunto inerente a um processo longo de luta pela soberania dos povos inseridos num Território-Nação que teve sua origem a partir dos imaginários do capital colonial português. $\mathrm{Na}$ prática há que se contextualizar o problema da terra em Moçambique que a sua solução exige a reforma agrária. De acordo com Newitt (1995), o território de Moçambique é produto de destruição das sociedades africanas, outrora organizadas política e socialmente com base em aldeias governadas pelos chefes de linhagens (NEWITT, 1995, p. 47). Como corolário dessa ação destrutiva os povos originários foram subdivididos, e houve tentativas de agrupá-los em três povos africanos - os Makuwas, a norte de Zambeze, e no sul os Carangas e os Tongas. Por outro lado, há que se salientar que, no período em que os povos originários estavam subdivididos, isto é, entre 1891 a 1975 eram consideradas propriedade do regime colonial português. Administrativamente, o estatuto do território era de província ultramarina. Nesse contexto, a conquista da independência em 1975 constituiu um dos marcos mais importantes no processo de luta e de resistência contra a dominação estrangeira, ao ponto de esse evento ter sido interpretado como a "libertação do homem e da terra". Assim, com a conquista da independência renasceu uma oportunidade para os sujeitos excluídos, integrantes dos grupos de famílias das etnias makuwas, carangas e tongas, participarem dos processos de decisão, mas agora fundidos no projeto de um território único - Estado-nação livre de sociedades chamadas tribais (MACARINGUE, 2018).

É importante apontar que a conquista da independência moçambicana referiu-se a um território edificado para servir interesses coloniais ao mesmo tempo em que concretizou a libertação do homem e da terra, desconsiderando o regime de propriedade privada sobre a terra.

O poder instaurado após a independência tenta edificar uma nova sociedade, e, por circunstâncias que não cabem neste texto serem discutidas, escolheu o socialismo como ideologia a ser seguida. No plano das mudanças pretendidas, traçou-se a diversidade étnica e tribal como parte das forças de atraso que iriam atrapalhar o projeto de unidade nacional. Assim, estas forças da diversidade deveriam, pelo novo regime não colonial, ser superadas. No contexto da economia surgiram problemas a serem geridos pelo governo como o fato de que os empresários desejavam converter o campesinato em classe operária. A este respeito foram tomadas medidas radicais a exemplo da socialização do campo, que violentou as comunidades e sobretudo os sujeitos que viam com bons olhos os projetos com os quais o governo não concordava. Há que se dizer ainda que na maior parte das políticas de emancipação, ainda que não fossem controversas, não houve o cuidado de acompanhá-las tal como seria necessário. Estes problemas foram agravantes para a guerra de desestabilização, que de fato acabou sendo um conflito de contestação das ideias socialistas.

Durante o período em que o país esteve submetido à esta guerra a economia ficou completamente paralisada (ABRAHAMSSOM; NILSSON, 1994). Não houve condições para concretização de um projeto de organização acima das aldeias comunais, que Negrão (2008) cita como tendo fracassado devido à falta de um acompanhamento adequado por especialistas em desenvolvimento rural e educadores de campo, como inicialmente havia sido projetado após a independência ocorrida em 1975.

No fim da década de 1980 o Governo foi forçado a abandonar algumas ideologias socialistas, como as políticas de economia centralizada e políticas protecionistas. Com a abertura de mercado foi que efetivamente o debate do território entrou em conflito, exigindo um reajustamento das políticas até então vigentes.

Outrossim, o fim da guerra interna permitiu à população deslocada e refugiada em outros países o retorno às suas zonas de origem. Esse fenômeno foi determinante para o surgimento de novas ocupações e, 
consequentemente, surgimento de novas comunidades locais. Essa mobilização, se por um lado deu início a reconstituição das comunidades locais desintegradas, por outro, sinalizou a ocorrência de conflitos de terras com raízes tanto históricas quanto recentes, tal como sucedeu em propriedades coloniais e nos bairros periféricos dos centros urbanos. A chegada de organismos de ajuda humanitária foi acompanhada com o surgimento de novos interesses econômicos, ascensão do turismo e impulsionamento da agricultura comercial. Como produto desses fenômenos combinados, passou-se a ouvir gritos de reclamações e fóruns de debate de terras. Novas instituições nasceram e pode-se apresentar destaque para a União Nacional de Camponeses (UNAC), a União Geral das Cooperativas de Maputo (UGC) e a Organização de Ajuda Mútua (ORAM).

Foi efetivamente esse movimento de debate que determinou a concepção do atual pacote legislativo e que criou condições para o reconhecimento da categoria de Comunidade Local, sem alterar o regime jurídico de posse de terra determinado com a adoção da Constituição da República Popular de Moçambique em 1975.

Realmente, o artigo 109 da Constituição da República, concebida em 2004, e o artigo $3^{\circ}$ desta mesma Lei de Terra, $n^{\circ} 19 / 97$ determinam o regime jurídico de posse estatal de terra e proíbem a sua venda, como também, o seu uso como objeto de alienação, hipoteca ou de penhora.

A terra é propriedade do Estado. A terra não deve ser vendida, ou por qualquer outra forma alienada, nem hipotecada ou penhorada. Como meio universal de criação da riqueza e do bem-estar social, o uso e aproveitamento da terra é direito de todo o povo moçambicano (MOÇAMBIQUE, 2004).

O artigo 3 da Lei de Terra, $n^{\circ}$ 19/97 estabelece que "a terra é propriedade do Estado e não pode ser vendida ou, por qualquer forma alienada, hipotecada ou penhorada (MOÇAMBIQUE, 1997).

Entre 1995, ano em que foi concebida a atual política de nacional de terra, e 2017, ano em que foi lançado o debate da possível revisão da PNT, qual a experiência acumulada no âmbito da gestão de terra? Entre 1997 a 2017, somam-se trinta anos de Lei de Terras, reconhecida como inovadora por reconhecer direitos costumeiros e ocupações de boa-fé. Portanto, neste cenário complexo a União Nacional de Camponeses aproveitou a ocasião para um encontro de reflexão.

Da IX Sessão do Fórum de Consultas sobre Terras até o lançamento do Processo de Auscultação Pública sobre a Revisão da Política Nacional de Terras passaram-se três anos. No entanto, não é de domínio público o que está na pauta do debate. O que é de domínio público é que, cada vez que se fala em aprovação de um investimento, seja ele público ou privado, ou ainda, os ditos megaprojetos, os mais desejados e acarinhados pelos governantes, que requerem para sua implementação grande extensão de terras nas áreas onde se instala, os sujeitos lá fixados, na sua maioria camponeses, são forçados a abandonar seus territórios, onde estão edificadas as machambas e seus espaços sagrados, que incluem cemitérios, matas sagradas e florestas comunitárias.

Com base no que foi acima descrito, pode-se dizer, sem nenhum remorso, que a aprovação e a subsequente concretização de determinados investimentos privados e públicos, com particular destaque para os megaprojetos, é carta branca para desintegração das comunidades locais. O processo de desintegração das comunidades locais, no âmbito de territorialização dos megaprojetos não é um fenómeno novo. A única novidade é a linguagem que é usada, tal como atesta o termo de reassentamento das comunidades locais.

A expressão reassentamento das comunidades locais transmite a ideia de deslocamento de todos os membros que compõem uma determinada comunidade local sem alteração das formas em que ela se apresentava. Embora a lei $n^{\circ}$ 19/2007 de 18 de julho, coadjuvado com o Decreto $n^{\circ}$ 31/2012 que defina o reassentamento como "a deslocação ou transferência da população afetada de um ponto do território nacional a outro, acompanhada de restauração ou criação de condições iguais ou acima do padrão anterior de vida", os fatos mostram que os reassentamentos são na realidade mecanismos de desintegração das comunidades locais.

O conceito de uma Comunidade Local destaca os seguintes elementos: agrupamento de famílias e indivíduos, que formam uma circunscrição territorial, que lutam pela salvaguarda dos interesses comuns através da proteção das áreas habitacionais, áreas agrícolas, sejam cultivadas ou em pousio, florestas, sítios de importância cultural, pastagens, fontes de água e áreas de expansão. Com base no conceito percebe-se que um "agrupamento de família" não se trata de uma montagem simples de agregados familiares, tal como tem sucede com assentamentos das comunidades afetadas pelas atividades económicas. Os assentamentos das comunidades afetadas pelas atividades económicas reproduzem as 
relações impostas durante a implementação dos programas de aldeamentos coloniais, como ainda, no âmbito da "socialização do campo" (MOSCA, 1996; NEGRÃO, 2008) que a FRELIMO (Frente de Libertação de Moçambique) impôs quando assumiu o poder em 1975. Por outro lado, há que se entender que o espaço de uma comunidade local é uma construção histórica, desenvolvida considerando os interesses das famílias que a compõem e com a base de princípios que primam pela valorização cultural e pelo equilíbrio ecológico.

Salta aos olhos que no rol das inquietações populares neste tocante, algumas das reclamações mais colocadas sejam relativas às indenizações, consultas públicas malconduzidas e queixas de arbitrariedades, que se compadecem com atos criminais, cometidas pelos funcionários públicos envolvidos nos processos de atribuição dos direitos de uso e aproveitamento de terra.

Tudo indica que, de fundo, há uma ruptura com o direito ao território. E este é o motivo pelo qual nos esforçamos em evidenciar como está estruturado este direito, em seus aspectos gerais, em Moçambique.

\section{TERRITÓRIOS MOÇAMBICANOS}

$\mathrm{Na}$ tentativa de compreender as concepções territoriais, consideramos primeiro partir-se com a noção genérica do que é território. Em seguida busca-se as concepções mais dominantes que comandam o sistema-mundo moderno, e por último, apresenta-se a concepção que é assumida em Moçambique e suas contradições.

Tal como Souza (2013) disse, a palavra "território" permanece sendo usada de modo bastante amplo. Cotidianamente "território" pode se referir simplesmente, a uma "grande extensão de terra". O autor afirma, que essa acepção é a "primeira e consta do Dicionário Houaiss da Língua Portuguesa" (SOUZA, 2013, p.77). Noutra busca, desta feita, no Dicionário Aurélio Básico da Língua Portuguesa, extraímos as seguintes definições:

S. m extensão considerável de terra; Área de um país, ou estado, ou província, ou cidade, etc.; Jur. base geográfica do Estado, sobre a qual exerce ele a sua soberania, e que abrange o solo, rios, lagos e mares interiores, aguas adjacentes, golfos, baias e portos; Jur. A parte juridicamente atribuída a cada Estado sobre os rios lagos e mares contíguos, e bem assim o espaço aéreo que corresponde ao território, até a altura determinada pelas necessidades da política e segurança do país, devendo-se, ainda, considerar como território os navios de guerra, onde quer se encontrem, e os navios mercantes em alto mar ou em águas nacionais (FERREIRA, 1988).

Como se pode observar, dois sentidos básicos são atribuídos ao "território" - o primeiro é referente a um objeto concreto - extensão de terra; o segundo - sentido jurídico, diz respeito a um imaginário humano, que transmite o sentido de posse. Da segunda acepção pode se perceber que "território" é um conceito de dimensão política, dado que, a partir dessa acepção, há um estabelecimento de relações entre os sujeitos reunidos num mesmo espaço territorial jurídico.

Se recorrermos às palavras de Souza (2013), de Haesbaert (1997) e de Raffestin (1993), deparamo-nos com o fato de que, para os três, o que define e delimita o "território" são as relações de poder.

No entanto, segundo a advertência de Marcelo Lopes de Souza (2013), considerar território como um espaço definido e delimitado por, e a partir de relações de poder é apenas uma primeira aproximação. Esta aproximação é necessária, mas insuficiente no esforço de conceituação teórica e geográfica. $O$ autor chama atenção para a necessidade de se questionar "quem domina, governa ou influencia e como domina, governa ou influencia esse espaço" (SOUZA, 2013, p.78, nosso grifo).

No debate dos autores aqui referenciados há um aspecto que interessa neste estudo, que tem a ver com a ação de territorialização, isto é, o processo de produção do território se dá por intermédio de dois fatores interdependentes: imagem projetada e poder. Em Souza (2013) assinala-se que,

O que "define" o território é, em primeiríssimo lugar, o poder. Ou, em outras palavras, o que determina o perfil do conceito é a dimensão política das relações sociais, compreendendo essa dimensão no sentido amplo de o político (le politique, das Politische), e não no sentido de a política (la politique, die Politik). O autor acrescenta que o que importa reter é que, por conta dessa dimensão política, não se justifica, pura e simplesmente, confundir o território com o substrato espacial material que serve de referência para qualquer (tentativa de) territorialização. Diversamente do substrato, os territórios não são matéria palpável, mas sim campos de força, que só existem quando durarem as relações sociais das quais eles são projeções especializadas. O verdadeiro 
Leitmotiv do conceito de território é político, e não econômico ou, como ocorre com o conceito de lugar, cultural-simbólico (SOUZA, 2013, p. 89).

O autor adverte para que não haja confusão entre o território como conceito e o substrato espacial material (as formas espaciais, os objetos geográficos tangíveis - edifícios, campos de cultivo, "feições naturais", etc.), ou ainda entre lugar e território. Não se pode imaginar que o conceito território esteja habilitado a dar conta de todas as facetas do espaço social, e para isso poderíamos também lançar mão de outras categorias geográficas.

Ao associar o quadro teórico do conceito de território, os processos que deram origem ao território moçambicano (quadro 1) e as relações sociais inscritas a partir do século XV até à atualidade, chegamos a conclusão de que o que hoje se assume como território de Moçambique (mapa 1) é na realidade uma estrutura que foi produzida para servir interesses alheios aos dos povos originários. Ou seja o mapa que temos não atende a população que já forjava sua existência antes da colonização portuguesa na região africana em que hoje se inscreve o território de Moçambique.

Quadro 1 - Estados e Reinos em Moçambique no Século XIX

\begin{tabular}{|l|l|}
\hline \multicolumn{1}{|c|}{ Estados/Reinos } & \multicolumn{1}{c|}{ Localização geográfica/ País vizinho } \\
\hline Estado de Gaza (mais extenso) & $\begin{array}{l}\text { Sul do Zambeze - África do Sul, Suazilândia, e } \\
\text { Zimbabwe }\end{array}$ \\
\hline Aringa da Maganja da Costa, Angoche & Zona Costeira da Zambézia \\
\hline Mwaliya, Komola, Maúa, Mataka & Interior de Cabo Delgado e Nampula \\
\hline $\begin{array}{l}\text { Gorongosa, Barué, Massingir, Carizamimba, } \\
\text { Macanga, }\end{array}$ & Margens do Rio Zambeze \\
\hline Mpezeni e Chicusse & Noroeste de Moçambique- Malawi, e Zâmbia \\
\hline Canhemba, Mataquenha, & Noroeste - Zâmbia e Zimbabwe \\
\hline
\end{tabular}

Fonte: MACARINGUE (2018).

O outro elemento que é problemático em Moçambique é a insistência em se avançar com o projeto de unidade nacional, a partir da negação da diversidade. No seio da sociedade moçambicana existe uma particularidade sociocultural, que é a diversidade étnica-linguística (KATUPHA, 1988; NGUNGA, 2012). A questão da diversidade sociocultural também é aplicável quando estamos diante do que Negrão (2008) denominou como sistemas costumeiros da terra em Moçambique. Em todo território nacional o autor apontou cinco sistemas costumeiros, que definem domínios territoriais, sendo eles: Sistema de Casamento Preferencial; Sistema de Territórios Consignados; Sistema de Estabilidade dos Descendentes Nucleares; Sistema de Segurança de Três Gerações e Sistema de Dependência do Grupo (NEGRÃO, 2008).

Em relação à diversidade étnico-linguística, vemos (mapa 2) que a territorialidade dos povos originários estabeleceu domínios territoriais cartografáveis. Por exemplo, as províncias de Maputo, Gaza e Inhambane, incluindo a cidade-capital - Maputo, por sinal, que cobrem a região Sul, fazem parte de uma mesma zona linguística - a T. Os grupos linguísticos desta zona são Tonga e Chope, Ronga, Thonga Tswa, Ndau. Na região Sul, ainda há um grupo linguístico Suazi, que faz parte da zona S, que domina uma pequena faixa na fronteira com a Suazilândia.

Na região Centro, a faixa banhada pelo rio Zambeze é conhecida como zona $\mathrm{N}$, sendo que os domínios linguísticos são Nyanja, Mazarro, Nsenga, Nyungue, Sena e Podzo. No Norte a maior parte da extensão territorial é dominado pelas línguas da zona P, nomeadamente, Yao, Maconde, Ndonde, Makuwa Maindo, Xuabo. Na extremidade superior à direita de Cabo Delgado, encontramos dois povos falantes de Swahili e Mwani pertencentes a zona G.

Como se pode observar, em Moçambique a concepção que se tem do território é a jurídica, que só reconhece a territorialidade institucional do sistema-mundo moderno, representado por organismos como a Organização das Nações Unidas (ONU) e a União Africana (UA). As categorias territoriais, fora do âmbito dos organismos, timidamente são debatidas em Moçambique, avaliando-se o que até então foi edificado, no âmbito da desconcentração e descentralização do poder.

As transformações ocorridas, em particular as inerentes aos governos provinciais, com a introdução das assembleias provinciais revelam apenas uma sobrecarga na despesa e pouca relevância na transferência 
dos órgãos do poder, o que não apresenta soluções palpáveis para os problemas que envolvem a categoria território em Moçambique.

\section{QUAL TERRITÓRIO DEVE CENTRAR O DEBATE EM MOÇAMBIQUE NO PÓS-INDEPENDÊNCIA?}

Moçambique, a exemplo de muitos outros países africanos que foram delimitados a partir dos interesses coloniais, está diante de conflitos de territorialidade. A implantação do Estado-nação, em si, já é uma contradição, dado que obedece a mesma lógica do sistema colonial. No atual contexto políticoadministrativo, que é continuidade de um processo que tem como origem a luta de libertação da situação colonial, assume-se que a concepção de um sistema de administração territorial esteja à altura das condições materiais, culturais e socioeconômicas existentes.

Neste estudo parte-se do princípio de que, do ponto de vista histórico material, o Estado-nação compreende a tríade território, autoridade e população. Esses três elementos ao se constituírem formam na essência uma unidade organicamente estruturada. O que tem causado a divergência de opiniões são os parâmetros que determinam o território, como também o problema de autoridade ou de poder.

Para discutirmos os contornos dessa tríade colocam-se aqui as seguintes questões: 1) como se efetivou a delimitação do território de Moçambique?; 2) em que bases ideológicas nasce o Estado de Moçambique?; 3) como tem se efetivado a relação governo e população ao longo do seu percurso histórico?

O Estado-nação é um produto em processo de formação. A sua fundação se inicia com a ocupação de um determinado espaço por uma comunidade, que com o tempo ganha complexidade do ponto de vista organizativo. Existem Estados menos complexos, como os que compreendem grupos étnicos. Os mais complexos são a maioria de Estados fundados nas contradições do sistema moderno-mundial: imperialismo e colonialismo.

A fundação de Moçambique obedeceu a essa lógica, tendo fundamentalmente ocorrido em duas etapas: a primeira, que se configura como o processo de ocupação e apropriação do espaço e, a segunda, marcada pela emergência da autoridade. Para este artigo, a delimitação das fronteiras ocorrida entre 1891 e 1975 foi considerada como uma etapa de processo formação do Estado-Nação.

$\mathrm{Na}$ etapa de delimitação do território os povos originários de matriz africana, que até o século XIX estavam organizados com base em estruturas tribais, compreendem os primeiros sujeitos que se fixaram neste espaço. Cada tribo, reino ou numerosas tribos e reinos, constituíam territórios autônomos. Em seguida, no âmbito das trocas comerciais que se realizaram a partir de determinados pontos ao longo da costa, surgiram territórios de mercadores asiáticos.

O fundamento ideológico e político é descrito por Ngoenha (1992) nos seguintes termos

$\mathrm{Na}$ origem de Moçambique, não estão as razões éticas e humanas, mas ideias de dominação de um homem sobre o outro, em nome de uma pretensa superioridade; quando um grupo de homens quer expandir a própria liberdade e, portanto, a própria história, sobre a liberdade e a história do outro homem (NGOENHA, 1992).

No horizonte dos que lideraram a luta de "libertação do homem e da terra" transfigura-se uma imagem de uma territorialidade consensual, ou seja, de um único território Moçambicano. Todavia, os conflitos armados que sistematicamente ocorrem em Moçambique podem ser interpretados como um sinal de que há divergências nas concepções de autoridade e/ou de território Moçambicano.

No esforço de edificar uma Nação Soberana (nós preferimos usar o termo coesa para este caso), nega-se a existência das diferenças: étnicas, tribais, religiosas, políticas, etc. Na esfera política o esforço atinente à implantação de democracia popular e emancipação foi notório, embora os procedimentos adotados geraram desconforto às próprias vítimas da colonização como um todo. Pode-se dizer que faltou aos proponentes a abordagem da Pedagogia do Oprimido de Paulo Freire (1974), que até aqui a sua adoção continua sendo um desafio em Moçambique. Os protagonistas da cena não privilegiaram os debates em múltiplas escalas, o que se transfigura é que assumiram uma legitimidade histórica circunstancial.

Evidentemente, com base em nossa proposta, essas questões não estão no centro de maior atenção. Ao se destacar os confrontos armados e os atos de sabotagem pretendemos chamar atenção o fato de que qualquer esforço de interpretação dos fenômenos sociais em Moçambique devem ter em conta os impactos que são gerados pelos conflitos armados: violência praticada pela tropa portuguesa em reação ao Acordo de Lusaka; guerra civil/desestabilização entre 1976 a 1992, agressões militares entre 1976 a 
1983 e os recentes ataques armados, o primeiro no Centro do país, entre 2013 a 2016 e o segundo, na região Norte de Moçambique, concretamente nos distritos de Mocímboa da Praia.

Se prestarmos atenção nos dois primeiros conflitos armados, um nas vésperas de proclamação da independência - violência praticada pela tropa portuguesa em reação ao Acordo de Lusaka, e um ano depois da sua proclamação, temos que admitir que o Estado-Nação de Moçambique já foi gestado com problemas. Tentaremos sugerir que essas duas enfermidades, no nosso entendimento, estão intimamente relacionadas com elementos constituintes do nosso objeto de estudo: o território e legitimidade política.

Na República de Moçambique pode-se dizer que as ideologias neoliberais determinam, de um modo geral, os rumos de vida de todos os grupos sociais. Todavia, há que se anotar que as relações sociais baseadas em princípios neoliberais não abarcam a totalidade do espaço Moçambicano, o que significa que há comunidades que as suas relações sociais são regidas com base em postulados não neoliberais.

O primeiro aspecto que sobressai é o da conectividade. Em cada uma dessas regiões os objetos espaciais de transportes implantados asseguram a conectividade entre os maiores centros urbanos com os locais de produção, sendo que estes podem estar dentro do país ou nos países vizinhos.

No Norte há, por exemplo, a ferrovia Nacala-Entre Lagos com os ramais Lumbo-Monapo; CuambaLichinga. Esses meios estabelecem a ligação aos interesses capitalistas, que continuam se apropriando das áreas que tinham sido concessionadas às companhias de plantações em Niassa, Cabo Delgado e Nampula. São destas infraestruturas de escoamento e corredores que falamos anteriormente.

Não obstante há possibilidades a partir de outros mecanismos, como é o sistema de fomento de culturas de rendimento. O Porto de Nacala se interliga com as mineradoras sediadas em Tete. Esse tipo de configuração dos meios técnicos e informacionais se repete em outras regiões. Na região central a ferrovia Beira-Machipanda no Zimbabwe, Beira-Moatize, os ramais Inhaminga-Maromeu e Sena-Vila Nova em Malawi, como ainda Oleoduto que conecta à Beira. Enquanto no Sul as ferrovias que estabelecem ligação com as Repúblicas da África do Sul (RSA), Zimbabwe e do Reino da Suazilândia. Essas três regiões, em parte coincidem com os três povos que formam três territórios identitários já mencionados.

Nos territórios dos Makuwas e dos Carangas o sistema colonial promoveu uma economia baseada em grandes plantações das culturas de algodão, chá, sisal etc. No entorno dessas plantações se incentivou o fomento do cultivo das mesmas culturas das grandes plantações, como ainda culturas alimentares. No território dos Tongas se incentivou uma economia de serviços, essencialmente de fornecimento de mãode-obra barata às minas da África do Sul.

Por outro lado, em todo o território, a forma como os objetos espaciais de utilidade pública, designadamente as rodovias, ferrovias, unidades sanitárias, escolas, foram implementados, não permitem a articulação entre esses meios com as sociedades rurais.

A configuração socioeconômica do território de Moçambique até 1975 expressa o projeto das grandes potências europeias materializada por meio de mapa "Cor de Rosas". Em 1976, na tentativa de converter esse cenário, o novo Estado-nação concebeu uma nova Constituição da República Popular de Moçambique, de modo que se adequasse ao projeto de um único território, fragmentado em meio rural/meio urbano; regiões norte e centro/sul. Um dos aspectos marcantes que foi introduzido pela nova constituição incide sobre a terra, pois esta foi nacionalizada, isto é, a terra passou a ser propriedade estatal.

Com esse regime legal da terra, para os camponeses como sujeitos que participaram diretamente no processo de luta, o seu significado foi de conquista de um dos principais meios de produção e de reprodução social. No entanto, a realidade deixada pelos capitalistas foi de um território configurado, do ponto de vista socioeconômica para responder aos interesses da metrópole. A rede de transportes, por exemplo, estava estruturada para assegurar a ligação entre os centros de produção e com os portos, por onde se exportava as matérias-primas. Em relação à rede de comercialização, pode-se dizer que por sua vez estava organizada para assegurar a recolha dos bens produzidos pelo campesinato, como também para a comercialização dos bens manufaturados no exterior, em particular, em Portugal.

Se por um lado, o Estado-Nação concentrava sua atenção no projeto de unidade territorial, ainda antes de sua consolidação, em 1976 o país mergulhou num conflito civil levado a cabo por alguns dissidentes que estiveram envolvidos na luta de libertação de Moçambique, que se organizaram no movimento da Resistência Nacional Moçambicana (RENAMO), partido que ainda hoje organiza a oposição à FRELIMO que detém a presidência da República desde a independência nacional. Esse conflito/guerra teve um impacto negativo nos esforços tendentes para acabar com as desigualdades regionais, pois provocou a 
destruição de objetos espaciais e, mais que isso, a morte de cerca de 1.500 .000 de pessoas, provocando também o despovoamento das comunidades rurais.

O conflito durou 16 anos e as consequências do foram de grande magnitude, pois atingiram severamente o tecido social do país. A estrutura socioeconômica edificada pelo regime colonial foi sabotada, principalmente nas áreas rurais. A população foi forçada a migrar do campo para as cidades, bem como também para países vizinhos. A economia ficou estagnada por este grande período.

Os motivos desse conflito são complexos. Alguns estudos associam esse conflito ao contexto regional e internacional. No plano regional, na vizinha África do Sul ainda vigorava o sistema político de segregação racial, o apartheid, o que significa que a independência de Moçambique representava perigo para esse regime. O mesmo se aplica para a Rodésia do Sul, atual Zimbábwe, que estava em guerra de libertação. As relações políticas entre Malawi e Moçambique não eram boas. A nível internacional o mundo estava em situação de Guerra Fria. Assim, a conquista de independência pelos países da África colocava em risco a reprodução capitalista, dado que, os países que se tornavam livres desencadeavam profundas reformas políticas, sendo que Moçambique se proclama socialista após a independência e o presidente Samora Machel apresentava relações com o socialista Fidel Castro.

Por fim, cabe ressaltar que as elites políticas ainda hoje, para se manterem no poder, adotam várias estratégias. Uma destas consiste em propalarem discursos de evocação da necessidade de unidade nacional, insistindo em projetos cujo horizonte é a implantação de sistemas de democracia burguesa. Por incrível que pareça, enquanto incitam o povo para pagarem os custos sociais do progresso pelo bem do país, os modelos de democracia pretendidos pelas elites são suportados em grande medida por financiamentos externos, respondendo, deste modo, aos interesses destes países financiadores, comprometendo a soberania nacional e agravando os históricos conflitos territoriais em Moçambique.

\section{CONSIDERAÇÕES FINAIS}

O processo histórico de formação moçambicana apresenta diversos aspectos, um pouco ilustrados neste artigo. E, hoje, a realidade de vinculação dos territórios campesinos ao agronegócio mundial decorre através de uma abordagem alicerçada no reconhecimento de uma única autoridade sobre o território, situação advinda desde a independência do país em 1975. Nesse sentido, o poder central é a única instância que toma decisões. Decorre daí que os territórios dos camponeses - comunidade locais, são inseridos na lógica de produção de commodities e agrocombustíveis.

Os territórios campesinos, isto é, as comunidades locais, ao serem qualificados na perspectiva natural savanas tropicais ou como corredor de desenvolvimento, são associados à uma imagem de que, na totalidade do território nacional, são espaços com potencialidades para uso, e que só eles é que reúnem condições de geração de elevadas quantidades de alimentos e commodities. Além disso, há um esforço no sentido de se evitar que ocorram abordagens a partir das especificidades de cada um dos grupos étnico-linguísticos: Yao, Makonde e Makwua.

Compreendemos, portanto, que os conflitos em Moçambique estão profundamente vinculados ao (des)entendimento dos territórios comunitários, diluídos em um projeto de país pouco afeito às peculiaridades destas diferentes expressões de viver. Não nos parece, pelo histórico arrolado neste texto, que seja possível falar de planejamento ou gestão territorial em âmbito administrativo sem que se (re)considere os territórios das comunidades locais em sua integralidade, como foi compreendida no pacote de legislação sobre terras no país; ainda que com profundas contradições.

\section{AGRADECIMENTOS}

Agradecemos à Coordenação de Aperfeiçoamento de Pessoal de Nível Superior - CAPES e ao Conselho Nacional de Desenvolvimento Científico e Tecnológico - CNPq pelas bolsas de doutoramento dos autores e pelo financiamento dos Projetos de Pesquisa ao qual se vincularam e possibilitaram trabalhos de campo em Moçambique. 


\section{REFERÊNCIAS}

ABRAHAMSSOM, Hans; NILSSON, Anders. Moçambique em transição: Um estudo da história de desenvolvimento durante o período 1974-1992. 1. ed. Maputo: CEGRAF, Maputo, 1994.

FREIRE, Paulo. Pedagogia do oprimido. São Paulo: Paz e Terra, 1974.

HAESBAERT, Rogério. Des-territorialização e Identidade: a rede gaúcha no nordeste. Niterói: EDUFF, 1997.

HARVEY, David. O novo imperialismo. Tradução de Adail Sobral e Maria Stela Gonçalves. $2^{\mathrm{a} e d . ~ L o y o l a . ~}$ São Paulo, 2005

KATUPHA, A. O panorama linguístico de Moçambique e a contribuição da linguística na definição de uma política linguística apropriada. In: Lua Nova. Maputo: Associação dos Escritores Moçambicanos. 1988, p. 27-32

MACARINGUE, Ernesto Jorge. Modernização da agricultura no distrito de Monapo em Moçambique no contexto de redefinição da geopolítica da fronteira agrícola mundial entre 2004 a 2017. Goiânia. 313 f. Tese (Doutorado em Geografia) - Universidade Federal de Goiás. Instituto de Estudos Socioambientais, Goiânia, 2018

MOÇAMBIQUE. Assembleia da República. Legislação Sobre Terra. Lei n 19/97. Regulamento da Lei de Terras Decreto, $n^{\circ}$ 66/98. 3. ed. Maputo: Imprensa Nacional, 2002.

MOÇAMBIQUE. Constituição da República (2004). Constituição da República de Moçambique. Lei no 19/97. Regulamento da Lei de Terras Decreto, n 66/98. 3. ed. Maputo: Imprensa Nacional, 2002.

MOÇAMBIQUE. Constituição da República. Boletim da República, 2004

MOÇAMBIQUE. Resolução $n^{\circ}$ 10/95 Aprova a política nacional de Terras e as respetivas estratégias de implementação. Maputo: Imprensa Nacional, 1995

Moçambique, Decreto $n^{\circ}$ 31/2012. Aprova o Regulamento Sobre o Processo de Reassentamento Resultante de Atividades Económicas. Maputo: Imprensa Nacional, 2012

Moçambique, Resolução no 19/2007 de 18 de Julho, Aprovada a Lei de Ordenamento do Território. Maputo: Imprensa Nacional, 2007

MOSCA, João. Evolução da agricultura moçambicana no período pós-independência. Lisboa: Universidade Técnica de Lisboa, 1996.

NEGRÃO, José. Repensando a terra e as modas do desenvolvimento rural. Maputo: Texto Editores, 2008

NEWITT, Malyn. História de Moçambique. Tradução de Lucília Rodrigues e Maria Georgina Segurado. Portugal: Publicações Europa-América, 2012.

NGOENHA, Severino Elias. Por uma Dimensão Moçambicana da Consciência Histórica. Porto: Edições Salesianas, 1992

NGUNGA, A. "Os desafios da investigação linguística em África: o caso de Moçambique". In: A Pesquisa na Universidade Africana no Contexto da Globalização: Perspetivas Epistemológicas Emergentes, Novos Horizontes Temáticos, Desafios. São Paulo: CEA-USP, 2012.

PRESIDÊNCIA. Comunicado. Disponível em <https://www.presidencia.gov.mz/por/Actualidade/PR-lancaprocesso-de-auscultacao-sobre-a-Revisao-da-Politica-Nacional-de-Terras > Acesso em 20/Jul/2020.

PROSAVANA. Elaboração do plano diretor do desenvolvimento agrícola no corredor de Nacala: nota conceitual. Maputo. 2013. Disponível em: <http://prosavana.gov.mz>. Acesso em: 3 jun. 2014.

RAFFESTIN, Claude. Por uma geografia do poder. São Paulo: Ática S.A. 1993.

SOUZA, Marcelo Lopes de. Os conceitos fundamentais da pesquisa sócio-espacial. Bertrand Brasil. Rio de Janeiro, 2013.

Recebido em: 20/09/2020

Aceito para publicação em: 22/11/2020 